\title{
ROTAÇÃO DE PERSPECTIVA: REFLEXÃO SOBRE ENSINO DE ANTROPOLOGIA PARA PROFESSORES INDÍGENAS
}

\author{
GIRALDIN $^{1 *}$, Odair \\ Universidade Federal do Tocantins (UFT)
}

\section{RESUMO}

Apresento aqui uma reflexão sobre a prática do antropólogo enquanto pesquisador e também como professor, abordando a delicada situação de ensinar Antropologia e seus princípios centrais como relativismo, alteridade e o trabalho de campo com observação participante para professores indígenas de diversos povos Macro-Jê do Brasil Central.

Palavras-chave: Ensino. Antropologia. Metodologia.

\section{ABSTRACT}

In this article, I make a reflection about the anthropologist practice as researcher and/or teacher, approaching the singular situation to teach, for indigenous teachers of Central Brazil Macro-Je peoples, the anthropological principles like otherness, relativism and field work with participant observation.

Key words: Teaching. Anthropology. Metodology.

\section{INTRODUÇÃO}

Este texto é uma versão ampliada e aprimorada de dois relatórios que escrevi em 2001, quando comecei a lecionar no curso de formação de professores indígenas do Tocantins, oferecido pela Secretaria Estadual de Educação. O primeiro relatório foi referente à etapa entre 23 e 27/04/2001, na cidade de Tocantinópolis. O segundo

1 * Professor da Universidade Federal do Tocantins, Campus de Porto Nacional no curso de História e coordenador do Núcleo de Estudos e Assuntos Indígenas (NEAI) e professor também no Programa de Pós-graduação em Ciências do Ambiente. Contato: giraldin@uft.edu.br. 
foi referente aos trabalhos realizados na etapa ocorrida entre 02 e 09/07/2001, na cidade de Paraíso do Tocantins. Naquele ano (e nos três anos seguintes), eu ministrei a disciplina de Fundamentos Antropológicos para os professores indígenas Krahô, Apinajé, Xerente, Karajá, Javaé e Xambioá.

E decidi publicá-los agora por duas razões principais. A primeira é no sentido de preservar as informações e a experiência vivenciada naquele período e que estavam guardadas já há quinze anos. Penso que elas podem servir para as pessoas compreenderem como lecionei aquela disciplina, assim como expressar minha satisfação de poder explicitar a trajetória de formação de alguns professores que participaram daquele curso naquele ano e que atualmente (2017) estão em graus avançados de suas formações acadêmicas. Chamarei a atenção para isso na conclusão do texto.

A segunda razão é que, ao publicar aqueles relatórios, quero compartilhar as reflexões sobre o ato de ensinar Antropologia para pessoas de povos com os quais normalmente nos relacionamos como pesquisadores antropólogos. Ou seja, reflexões sobre o dilema de ensinar as bases teóricas e metodológicas da Antropologia para algumas pessoas que, nas nossas atividades de pesquisadores, são os sujeitos das pesquisas e que nos fornecem as informações etnológicas que buscamos.

Trabalhar com a disciplina de Antropologia com representantes dos diversos povos indígenas existentes no Estado do Tocantins foi um desafio para mim. Eu percebi que, para realizar esta tarefa, teria que realizar uma certa "rotação de perspectiva" . Isto é, eu precisava pensar uma forma de trabalhar com os representantes dos povos indígenas os assuntos que nós, antropólogos, normalmente pesquisamos com eles, mas raramente conversamos com eles sobre isso.

Desde o início da minha preparação para este curso, refleti constantemente sobre como abordar esta questão com aquelas pessoas. Nestas reflexões, pensei que não poderia entrar na questão da mesma forma como eu a trabalhava com os estudantes não-

2 Tomo, muito livremente, essa ideia de rotação de perspectiva dos escritos de Florestan Fernandes nos quais ele refletia sobre as abordagens da revolução na América Latina, indicando que era preciso mudar a posição do olhar para poder entender toda a complexidade da Revolução Burguesa. Ao me ver, na situação de precisar ensinar os fundamentos antropológicos para professores indígenas, precisei mudar meu foco sobre esse campo de conhecimento e de minha própria formação dentro dele. 
indígenas nos cursos de graduação nas universidades em que atuava como professor ${ }^{3}$.

Com os estudantes não-indígenas, eu trabalho sempre partindo da perspectiva científica (que é o princípio norteador das atividades na academia). A partir deste princípio, procuro mostrar aos alunos como uma abordagem antropológica da humanidade, entendida como uma unidade biológica e ao mesmo tempo expressando uma grande pluralidade cultural, é mais promissora quando realizada de um ponto de vista relativista. Este ponto de vista é, ao mesmo tempo, universalizador (porque considera a humanidade uma unidade biológica) e particularizador (porque considera que cada povo ou grupo social tem suas próprias características culturais e deve ser respeitado neste ponto).

Bem, esta posição relativizadora (universalizadora), da perspectiva de uma Antropologia como ciência moderna e ocidental, é uma postura recente na história da humanidade e que precisa ser compreendida de forma particularizada. A Antropologia somente viria a acontecer no mundo ocidental após o Renascimento (dentro do movimento do Humanismo), mas principalmente após o Iluminismo. Ela é, então, um campo de conhecimento nascido, sobretudo, no século XIX.

Colocada a Antropologia dentro deste quadro, percebe-se que minha angústia residia em que, ao ensinar aos representantes dos povos indígenas uma visão científica sobre como estudar os povos, eu poderia estar atuando como uma forma de etnocentrismo. Afinal, eles, enquanto representantes de povos diferentes, devem ter seus próprios meios de compreender a diversidade cultural. Uma dúvida era: teriam eles uma visão universalizadora ou particularizadora da Humanidade? Mas outro problema se colocava: esta idéia de Humanidade é fruto de nossa tradição cultural ocidental. A maioria dos antropólogos afirma que para muitos povos indígenas a Humanidade acaba nas fronteiras do próprio povo ${ }^{4}$. E como, então, eu falar, com estes professores, de uma Humanidade única e uma pluralidade cultural?

\section{1 - Aprendendo a ensinar Antropologia aos Povos Indígenas}

Apesar destas reflexões, ou mesmo por conta delas, decidi que eu deveria tratar desta que é, acredito, a questão cerne da prática antropológica: refletir sobre a alteridade e a diversidade cultural.

3 Em 2001 eu era professor da Universidade do Tocantins (UNITINS) e da Universidade Luterana do Brasil (ULBRA).

4 Veja-se Lévi-Strauss, C. O Pensamento Selvagem. São Paulo, Papirus, 1989. 
Considerei um ponto que é tido também como crucial para uma compreensão identitária: o princípio da contrastividade. Como já mostrado por diversos autores, como Roberto da Matta (1997), este princípio da contrastividade está presente em todo momento da reflexão, pois a possibilidade de se construir uma noção de Eu depende da existência do Outro, com o qual se faz a contrastividade. Com o uso deste princípio, possibilita-se a comparação reflexiva, que permite compreender-se através da compreensão do Outro.

Dentro desta perspectiva da comparação contrastiva, introduzi o conceito de Antropologia procurando compará-la com outros ramos do conhecimento ocidental ao qual eles, enquanto estudantes, já haviam entrado em contato. Assim, comecei com a definição de alguns campos de conhecimento: Matemática: estudo dos números; Biologia; ciência que estuda (logia) os seres vivos (Bio); Ecologia; estudo (logia) das relações entre os seres vivos de um lugar (Eco); Geografia: estudo das relações entre o homem e o meio ambiente. Finalmente, depois destas defini a Antropologia como o estudo (logia) do Homem (Antropo). Mas este homem não como ser biológico individual, mas como conjunto dos seres humanos que vivem em sociedade. Assim, a definição corrente foi: Antropologia é o estudo dos seres humanos através da relação entre Sociedade e Cultura.

Após esta definição de Antropologia, construi com eles o conceito de sociedade. Através de um diálogo com os alunosprofessores, eles argumentaram que sociedade é a forma social de viver que cada povo possui. Neste ponto, solicitei que apresentassem qual o conceito que, na língua de cada etnia, corresponderia à palavra sociedade.

Definido o conceito de sociedade, ainda perdurava o de cultura. Eu senti que não poderia colocar a definição de cultura corrente no discurso antropológico atual: cultura como código simbólico. Acreditei que tentar explicar a eles o que seria um código e, depois, o que entendemos por simbólico, seria complicar demais. Cheguei a esta conclusão pela experiência docente com universitários não-indígenas que encontram enormes dificuldades em compreender aquela definição, mesmo que compartilhem todos da mesma tradição cultural e, também, do mesmo código simbólico do professor. A definição de cultura ocorreria no decorrer do próprio curso, como veremos adiante.

Dessa forma, escolhi trabalhar, com os professores dos povos Karajá (Karajá, Javaé e Xambioá), Apinajé, Krahô e Akwe-Xerente, 
com materiais e metodologia que permitissem a eles uma reflexão sobre Si a partir de uma observação do Outro. Para atingir este objetivo, selecionei diversos vídeos sobre povos outros existentes em outras partes do mundo.

$\mathrm{Na}$ primeira etapa, trabalhei apenas com textos em áudio e vídeos, e não com textos escritos. Exibi vídeos sobre diversas regiões da África (Povos e Lugares da África), que mostraram aos alunosprofessores a diversidade étnica e cultural daquele continente. Nesta série de vídeos, vimos que em Madagascar um grupo étnico realiza um ritual de des-sepultamento de ancestrais. Durante um ritual, aquele povo retira da tumba os ossos dos ancestrais sepultados. Depois de realizarem cerimoniais festivos, os ossos são novamente enrolados em tecidos e sepultados novamente. Com esta exibição, os Karajá nos informaram que eles também realizavam um enterro secundário: seis meses após o sepultamento primário, o corpo era desenterrado e seus ossos sepultados num vaso novo.

Também exibi um vídeo sobre a ilha de Bali e seus inúmeros templos, abordando amplamente a cosmologia do povo daquela região. Além disso, vimos também um vídeo sobre a Austrália e dois grupos de aborígenes daquele continente. Com estes vídeos eu objetivava possibilitar aos professores alunos uma ampliação (talvez uma tentativa de universalização da Humanidade) da visão étnica, procurando permitir a eles uma construção mais universal da humanidade. Pude perceber que a cada nova imagem de etnias diferentes e práticas rituais distintas, eles refletiam sobre a sua própria cultura.

Além de mostrar a existência de outras etnias em outros continentes, a escolha da África como principal local de contraste teve como objetivo exibir, posteriormente, um vídeo sobre prática religiosa e ritual dos povos africanos e afro-brasileiros (ou afrodescendentes). Neste sentido, escolhi o vídeo Atlântico Negro: Na Rota dos Orixás. Este vídeo mostra um pouco da história da transferência compulsória de africanos para o Brasil e também da deportação de afro-brasileiros do Brasil para Benin, após a Revolta do Malês ocorrida em Salvador (BA) em 1835. Além disso, o vídeo procura mostrar o quanto se preservou da religião do vodu em São Luís (MA), oriunda de Benin.

$\mathrm{O}$ ponto culminante do vídeo, enquanto um texto para reflexão, ocorreu quando da informação de que os africanos, antes de serem embarcados para a América, totalmente despojados de 
qualquer pertence material, deveriam dar voltas em torno da árvore do esquecimento. Acreditava-se que uma pessoa que viajasse para nunca mais retornar, não poderia continuar pensando em sua terra. Caso isso acontecesse, poderia causar desgraças para os que ficaram. Apesar deste ritual, o vídeo mostra o quanto a população africana reproduziu no Brasil, ainda que de forma transformada, formas sociais de viver (sociedade).

Partindo desta informação, foi que os levei a pensar num conceito de cultura: perguntei-lhes como poderiam os negros ter conseguido reconstruir alguma forma de viver aqui que tivesse semelhança com a forma de viver na África, uma vez que vieram sem nenhuma roupa, arma ou ferramenta. A resposta dada por Ijuraru Karajá foi: porque eles tinham uma linguagem; Curahá Xambioá emendou: eles tinham a memória e podiam se lembrar dos seus modos de viver. Assim, aproveitando essa discussão, defini com eles um conceito para cultura: a memória de um povo sobre a forma social de viver ${ }^{5}$. Aproveitando a mesma oportunidade, coloquei dois outros conceitos que são centrais para a visão antropológica: o relativismo e o etnocentrismo. Defini o relativismo como a atitude de respeito à diversidade cultural e às diferentes formas de viver em sociedade; já a definição de etnocentrismo foi que se trata de atitude de desrespeito as formas diferentes de viver em sociedade.

Após a exibição destes vídeos com povos distantes da realidade étnica dos alunos-professores, exibi então alguns vídeos sobre povos indígenas que vivem no Brasil: inicialmente os Araweté. Depois o vídeo 'A Arca dos Zo'é', sobre os Zo'é e os Waiampi. Em seguida, foi exibido o vídeo sobre os 'Panará: O Brasil Grande e os Índios Gigantes'. Para completar esta série, vimos também o vídeo 'Eu já fui seu irmão', sobre o encontro entre os Parakatejê e os Krahô. Para finalizar, assistimos a série de vídeos exibida pela TV Escola: 'Índios no Brasil'.

Este talvez tenha sido o vídeo que causou maiores repercussões, sobretudo pela presença de opiniões dos não-índios sobre a população indígena, mas, principalmente, porque o vídeo demonstra uma apreciação positiva e de valorização da autoestima dos povos indígenas. Dentre os povos indígenas que vivem

5 Preferi uma definição assim àquela semiótica mais corrente nas abordagens antropológicas, como sendo um sistema simbólico pelo qual um povo pensa o mundo, age no mundo e interpreta suas ações e as das demais pessoas. 
no Tocantins, o povo Karajá-Xambioá talvez seja uma etnia que mais tem sofrido transformações negativas ao longo da sua história (Giraldin, 2002). As maiorias dos seus membros são evangélicos e não falam mais a sua língua materna, nem tampouco praticam seus principais rituais, uma vez que eles se confrontam com os princípios cristãos.

No entanto, pude perceber que pelos menos um dos representantes Xambioá (o professor Curahá) refletiu longamente sobre o processo que os levou a quase perder a língua materna. Após assistir ao vídeo que mostra como as missões jesuíticas forçaram os Pankararu a abandonar sua língua; como os católicos pressionavam os povos do alto rio Negro para que abandonassem sua língua; como os funcionários do SPI também atuaram para a perda da língua Kaingang no sul do Brasil, Curahá refletiu e informou que sua avó lhe contava que ela, quando menina, fora levada de sua aldeia para um internato em Conceição do Araguaia, somente saindo dali depois de grande.

\section{2 - Ensinando a fazer (e porque fazer) Antropologia}

Compartilho da ideia de Clifford Geertz (1978) de que fazer Antropologia é fazer etnografia. E fazer etnografia é produzir descrições densas da realidade estudada, através do aprofundamento da compreensão do assunto que investigamos e da sua apresentação textualizada. Esta textualização pode ser na forma de um discurso escrito, oral ou imagético. E para produzir uma descrição densa as noções de alteridade, diversidade, relativismo, sociedade, cultura, além do trabalho de campo, são noções básicas.

Dentro do objetivo de levar, através das noções básicas apontadas acima, a uma reflexão constrastiva, finalizei a etapa dando aos alunos-professores a tarefa de fazer antropologia, ou de produzir etnografia. Solicitei a eles que realizem uma pesquisa em seus povos sobre alguns pontos, como pode ser visto adiante.

Cada grupo de alunos-professores, divididos por seus povos, deveria pesquisar e estudar a cultura e sociedade de outro povo, da seguinte maneira: o grupo do povo Karajá estudará a cultura e sociedade do povo Apinajé. Estes, por sua vez, estudarão aqueles. O grupo de alunos-professores Akwẽ-Xerente estudará a cultura e sociedade do povo Krahô e vice-versa. 
A relação a seguir é de temas básicos sugeridos por mim para servir como ponto de partida e parâmetro para todos os alunosprofessores. Nada impediria que houvesse uma ampliação dos temas a serem abordados, de acordo com o entendimento de cada povo.

Assuntos e questões que deveriam ser pesquisados:

1) Cosmologia e religião.

- Qual a origem do mundo?

- Como o mundo está organizado?

- Quantos espaços têm no mundo (quantos céus e quantas terras existem)?

- Como é a relação entre as coisas materiais e as espirituais?

- Como ocorre a morte e qual o destino final da alma dos mortos?

- Quais são as ideias sobre a formação do corpo das pessoas?

- Como se forma o corpo dentro da barriga da mulher?

- Quando é que começa a vida?

- O que é ter uma vida saudável?

- Como acontecem as doenças?

- Como podem ser feitas as curas das doenças?

2) Organização Social e Política.

- Como é o sistema de parentesco?

- Como se formam os grupos de parentes por sangue (Quem são considerados parentes pelo sangue)?

- Como ser formam os grupos de parentes por motivos da cultura? 
- Quais são os grupos (ou partidos) em que se divide a comunidade?

- Quais são os nomes de pessoas que a comunidade usa? Esses nomes são transmitidos ou são inventados? Como se transmitem?

3) Cerimônias mais importantes do povo.

- Como é a cerimônia? Descrever

- Explicação do significado da cerimônia.

Estas pesquisas apenas tiveram início durante o encontro. Cada grupo levou uma cópia dos itens acima, que deveriam pesquisar até o próximo encontro. Durante o mês de julho, cada grupo de cada povo deveria ter as informações necessárias para poder ensinar (como um informante) aos membros do grupo de outro povo. Ao mesmo tempo, cada grupo teria que obter informações deste outro povo sobre sua sociedade e cultura (como um antropólogo faz em seu trabalho de campo).

Assim, como resultado final, teríamos uma experiência de uma etnografia dos Karajá feita pelos Apinajé; uma etnografia dos Apinajé realizada pelos Karajá; uma etnografia dos Krahô produzida pelos Xerente e uma etnografia dos Xerente construída pelos Krahô.

Por sugestão do professor Dodanim Alves Pereira Krahô, ficou estabelecido que cada grupo poderia apresentar o trabalho final escrito em português e na língua materna do grupo do pesquisador. Desta forma, teríamos, ao final do curso, as etnografias citadas acima escritas em português e nas línguas indígenas. Acredito que este poderia ser um material muito importante para auxiliar os professores indígenas a ensinarem seus alunos sobre a diversidade étnica e cultural do Brasil (em geral) e do Tocantins (em particular).

Portanto, à guisa de conclusão do que foi a primeira etapa deste curso, gostaria apenas de citar o exemplo de um episódio acontecido na etapa de Tocantinópolis e o quanto a reflexão a partir da perspectiva relativista e de respeito à diversidade cultural pode elevar a autoestima e a autoafirmação dos povos indígenas.

Eu não estava presente, mas fui informado de que numa das refeições servidas aos alunos-professores, constava do cardápio um ensopado de peixe. Creio que a intenção dos organizadores foi a 
melhor possível. Afinal, peixe é um alimento muito apreciado por todos, sendo esta a base de fonte de proteína para o povo Karajá. Ocorre, entretanto, que o peixe servido naquela refeição foi um peixe de couro (parece-me que foi jaú). Alguns Karajá recusaram comer. Este peixe, segundo foi informado depois por Ijuraru Karajá, é um dos que estão na lista dos tabus alimentares daquele povo. Os únicos peixes de couro que eles consomem são: surubim e mandis pequenos.

No final da etapa o mesmo Ijuraru, motivado pelas aulas nas quais discutimos relativismo e etnocentrismo, perguntou-me se seria possível recusar comer alguma comida oferecida por um nãoíndio, quando estivessem fora da aldeia. Eu respondi que eles tinham todo o direito de fazer isso. Acredito que esta iniciativa de Ijuraru de levantar esta questão se deu pelo nível das discussões ocorridas durante a disciplina. Percebi que ele compreendeu que tinha o direito de ser respeitado na sua diferença cultural. Fiquei feliz com isso.

Assim foi a primeira etapa desta disciplina de Fundamentos Antropológicos. A segunda aconteceria somente, em julho de 2001. Porém, como veremos, não exatamente como havíamos planejado.

\section{Praticando escrever antropologicamente (etnograficamente)}

Os alunos-professores voltaram para a etapa de Paraíso com informações sobre os aspectos culturais de seus povos. Nesta turma, existia apenas um representante da etnia Krahô: o aluno-professor Dodanim Alves Pereira Krahô. Devido a atividades em sua aldeia, ele não pode participar da etapa de Paraíso do Tocantins. A ausência dele levou a uma reformulação no plano inicial. Como a atividade consistiria em os Xerente escreverem um trabalho sobre os Krahô (e vice-versa), enquanto que os Apinajé escreveriam sobre os Karajá (e vice-versa). Com a ausência de Dodanim, a saída encontrada, numa conversa com os membros da turma, foi que cada povo escreveria dois trabalhos, sendo um sobre cada povo: os Xerente escreveriam sobre os Karajá e os Apinajé; os Apinajé escreveriam sobre os Karajá e Xerente; os Karajá escreveriam sobre os Apinajé e os Xerente.

Esta opção mostrou-se muito interessante, muito embora mais trabalhosa para os alunos-professores. Se por um lado todos puderam participar ouvindo a exposição dos membros das outras etnias, por outro tiveram que produzir dois trabalhos escritos.

As apresentações seguiram o roteiro previamente apresentado na etapa de abril em Tocantinópolis. Cada uma durou um dia todo 
e um ponto a ser observado foi que as partes que consumiram mais tempo foram aquelas que ser referiram à cosmologia. As diversas histórias e contos sobre a origem de todos os elementos do universo são algo que fascina não somente aos antropólogos, mas também aos membros dos outros povos. Nos comentários que se seguiam às apresentações, podia se ouvir as observações sobre as semelhanças e diferenças existentes entre a versão apresentada e aquela do povo de quem ouvia.

O xamanismo, que se refere tanto à relação entre as coisas materiais e as espirituais, quanto àquelas explicações de como acontecem as doenças, como podem ser feitas as curas, como ocorre a morte e qual o destino final da alma dos mortos, foram assuntos que consumiram bastante tempo nas apresentações. Isto é também facilmente explicável pela concepção sociomórfica do universo, ou seja, a ideia de que todos os elementos estão interligados por corpos diferentes que mantém um fator em comum: a presença de um mesmo princípio vital. Este tema tem presença marcante em praticamente todos os povos indígenas das terras baixas da América do Sul, conforme já escreveu Viveiros de Castro (2002).

Os primeiros a se apresentarem foram os Karajá. O principal apresentador foi Kurikalá, uma vez que houve atraso na chegada dos demais Karajá das aldeias de Fontoura e Santa Isabel. Suas informações foram complementadas, posteriormente, sobretudo pelos ensinamentos de Ijuraru. A ausência de grupos cerimoniais entre os Karajá, semelhantes aqueles encontrados entre os Apinajé e Xerente (metades ou grupos cerimoniais masculinos) não chamou tanto a atenção dos Apinajé e Xerente, quanto a origem dos Karajá. De acordo com suas histórias, eles são descendentes dos que migraram de um plano inferior existente abaixo das águas do Araguaia, para este ocupado atualmente. Além disso, chamaram muito a atenção as formas de sepultamento e destino final da alma dos mortos, as quais, para os Karajá, não abandonam os vivos. Ao contrário, para eles os membros antigos dos mortos das famílias acompanham os vivos em suas tarefas diárias.

Os segundos a se apresentarem foram os Apinaje. A sua cosmologia é diferente daquela dos Karajá, sobretudo na origem, a partir da criação feita por Sol e Lua, o que chamou a atenção dos membros dos demais povos.

Os últimos foram os Xerente. Sua cosmologia não difere muito daquela dos Apinaje, no que se refere à presença de dois 
heróis criadores dos elementos do universo. Há um ponto, entretanto, diferente. Eles acreditam na existência de um plano terrestre inferior e outro superior ao atualmente ocupado pelos humanos. O plano inferior é evidenciado pela história do homem caçador que cavou um buraco de tatu e caiu. Muito embora esta história exista também entre os Apinajé, entre os Xerente o homem consegue retornar juntamente com uma vara de queixadas, após aprender as habilidades xamâmicas com o chefe-controlador dos queixadas.

O plano superior tem como evidência de sua existência a história da mulher-estrela ${ }^{6}$, cuja história também existe entre os Apinajé e os Karajá. Diferentemente dos Xerente e Apinajé, para os Karajá na história de Tainahakȳ é um homem que desce do céu e ensina o cultivo e a utilização das plantas comestíveis. O que chamou mais a atenção dos Apinajé e Karajá, nas descrições feitas pelos Xerente, foi o sistema de clãs e a filiação patrilienar. Está é uma característica que os diferencia dos outros dois povos e foi demorado e difícil para os alunos-professores Karajá e Apinajé compreenderem a existência e o funcionamento dos clãs e dos grupos cerimoniais masculinos. Ponto clímax da apresentação dos Xerente foi quando o professor Bonfim, após minha insistência, executou um trecho do discurso cerimonial Xerente, o qual é também uma marca distintiva da chefia Akwẽ (Xerente e Xavante).

\section{As descrições etnográficas}

Após as apresentações, os alunos-professores dedicaram-se a construir os textos sobre as descrições feitas pelos representantes dos demais povos.

Num determinado momento José Hani Karajá mencionou se não seria mais importante para os outros povos que cada um tivesse escrito sobre a sua própria cultura e oferecido este texto para as demais. Eu argumentei que não fora esta a intenção, pois eu queria que cada um dos alunos-professores pudesse se dedicar a estudar os outros povos, como um exercício de abordagem da alteridade.

Acredito que esta tenha sido uma boa opção. Segundo as informações dos próprios alunos-professores, eles ainda não haviam tido a oportunidade de se conhecerem culturalmente, muito embora

6 Essa temática foi apresentada em um livro publicado pelo Núcleo Takinahakỹ (Pimentel da Silva, 2012). 
estejam juntos neste curso há mais de quatro anos. Caso seguisse a sugestão de José Hani, eles não teriam tido a oportunidade de expor oralmente suas características culturais, ao mesmo tempo em que os membros dos demais povos não teriam tido a oportunidade de refletir sobre a sua própria sociedade e cultura através da reflexão a partir da alteridade.

Os textos foram feitos, numa primeira versão, em português. Agora pretendo desenvolvê-las para que os autores as traduzam para suas línguas maternas. Desde a sua produção, nunca mais voltei a trabalhar com esses textos que ainda não foram publicados. Pretendo ver este material vem a publico, para que possa servir como material de trabalho nas escolas indígenas.

\section{CONSIDERAÇÕES FINAIS}

Escrevi no primeiro número desta revista (Articulando e Construindo Saberes) que os alunos-professores que frequentaram (e frequentam) o Curso de Educação Intercultural da UFG demonstravam grande interesse em pesquisar sobre seus próprios povos, após serem instigados a refletirem sobre si mesmos nas atividades realizadas durante o curso (Giraldin, 2016). Alguns dos alunos-professores aqui citados já partiram para outro plano, como o saudoso professor Ijuraru, cuja serenidade e sabedoria eu nunca esquecerei.

Outros seguiram em frente em seus estudos e galgaram graus mais altos de formação, como José Hani Karajá, que concluiu mestrado em Ciências do Ambiente, na Universidade Federal do Tocantins (UFT), a quem tive a honra de orientar. Também Cassiano Sotero Apinajé, que se graduou em Pedagogia na UFT, também cursa o mesmo mestrado na UFT e também sob minha orientação. A professora Creuza Prumkwyj Krahô está concluindo seu mestrado em Desenvolvimento Sustentável no CDS/UnB. Mais recentemente vemos agora uma nova geração de jovens estudantes indígenas também galgando esses degraus mais altos da academia. Renato Yahe Krahô está concluindo seu mestrado em Ensino de Línguas, na UFT, campus de Araguaína. Letícia Jokahkwyj Krahô e Júlio Kamer Ribeiro Apinajé iniciam seus mestrados em Antropologia Social na UFG, no primeiro semestre de 2017. E Ricardo Tewaxi Javaé também inicia seu mestrado em Ciências do Ambiente na UFT, também neste primeiro semestre de 2017. 
Comisso, vemos que a crescente capacitação dos pesquisadores indígenas como pesquisadores, nos permite compreender a importância da formação antropológica para suas inserções no mundo acadêmico, tanto quanto para suas atividades docentes nas escolas indígenas sabendo valorizar e estimular os conhecimentos indígenas e sua manutenção na vida das suas comunidades, bem como sua inserção como parte dos conhecimentos a serem trabalhados nas aulas formais nas escolas.

\section{REFERÊNCIAS}

DA MATTA, Roberto. Carnavais, Malandros e Heróis. Para uma sociologia do dilema brasileiro. RJ, Rocco, 1997.

GEERTZ, Clifford. A interpretação das culturas. RJ, Zahar editores, 1978.

GIRALDIN, Odair. "Catequese e Civilização. Os capuchinhos "entre" os "selvagens" do Araguaia e Tocantins." Boletim do Museu Paraense Emilio Goeldi (Antropologia). Vol 18 (1), 2002. pp. 27-42

GIRALDIN, Odair. "Alfabetização pelos conhecimentos indígenas: reflexões sobre suas possibilidades e limitações". Goiânia/UFG - Articulando e Construindo Saberes. Vol 1. N. 1, 2016. pp 15-20

LEVI-STRAUSS, Claude. O Pensamento Selvagem. São Paulo, Papirus, 1989.

PIMENTEL DA SILVA, Maria do Socorro (org). Histórias Indígenas. Goiânia, Editora Espaço Acadêmico, 2012.

VIVEIROS DE CASTRO, Eduardo B. A Inconstância da Alma Selvagem e Outros Ensaios de Antropologia. São Paulo: Cosac \& Naify, 2002. 552 pp. 